\title{
AGROTÓXICOS: INEFICIÊNCIA DA GOVERNANÇA ABERTA OU INTERESSE NO OBSTÁCULO À INFORMAÇÃO?
}

AGROCHEMICALS: INEQUICIENCY OF OPEN GOVERNANCE OR INTEREST IN OBSTACLE TO INFORMATION?

Renato Maso Previde ${ }^{1}$ Cildo Giolo Júnior ${ }^{2}$

ISSUE DOI: $10.21207 / 1983.4225 .407$

\section{RESUMO}

Há nítidas semelhanças no desenrolar dos problemas havidos pelo uso de agrotóxicos tanto no Brasil quanto na França. A desinformação prestada pelo governo, nos dois países, é que parece ter objetivos diferentes. Enquanto na França há uma dispersão de dados oferecidos pelo próprio governo, no Brasil a situação inverte-se, por intermédio da governança aber-

\footnotetext{
${ }^{1}$ Possui graduação em Direito pela Faculdade de Direito de Franca (1998) e mestrado em Direito Econômico das Relações Empresariais pela Universidade de Franca (2006). Atualmente é advogado - Ordem dos Advogados do Brasil, professor da PUC/MG, professor convidado da especialização em Processo Civil Empresarial da Faculdade de Direito de Franca e professor do EaD da Universidade Federal de São Carlos. Tem experiência na área de Direito, com ênfase em Direito Empresarial e Civil.

${ }^{2}$ Doutor em Direito pela Universidade Metropolitana de Santos (Unimes), tendo defendido sua tese em 2013. Doutor em Ciências Jurídicas e Sociais pela UMSA (Buenos Aires Argentina), tendo defendido sua tese em 2006. Mestre em Direito Público (Direitos do Estado no Estado Democrático de Direito) pela Universidade de Franca (2001). Pósgraduado "lato sensu"; em Direito Processual Civil na Faculdade de Direito de Franca (1994). Graduado em Direito pela Faculdade de Direito de Franca (1991). Professor Titular da cadeira de Direito Civil I na Faculdade de Direito de Franca. Advogado. Avaliador do MEC/INEP para os Cursos de Direito.
} 
ta que existe no país. O detalhamento dos dados no Brasil não passa, diretamente, pelo próprio governo, mas por intermédio de outros organismos que propagam tal informação sejam organizações não governamentais, a imprensa ou órgãos do poder público mais identificados com a sociedade. Assim, o levantamento de dados faz surgir essa distinção sobre o que será concluído ao final, em relação aos dados apurados quanto à utilização dos agrotóxicos: ineficiência da governança aberta ou interesse no obstáculo à informação?

Palavras-chave: Agrotóxicos. Poder Público. Informação. Governança. Aberta. Democracia.

\section{ABSTRACT}

There are clear similarities in the development of the problems caused by the use of agrochemicals in Brazil and in France. The disinformation provided by the government in both countries is that it seems to have different objectives. While in France there is a dispersion of data offered by the government itself, in Brazil the situation is reversed, through the open governance that exists in the country. The details of the data in Brazil do not go directly through the government itself, but through other agencies that disseminate such information are non-governmental organizations, the press or public bodies more identified with society. Thus, the data collection draws this distinction on what will be concluded at the end, in relation to the data on the use of pesticides: inefficiency of open governance or interest in the obstacle to information?

Keywords: Agrochemicals. Public Power. Information. Governance. Open. Democracy.

\section{INTRODUÇÃO}

O desenvolvimento socioeconômico da humanidade determina a utilização de técnicas produtivas agrícolas que projetem o aumento da produção ou condições mais eficientes de trabalho no intuito da persecução do lucro.

O caráter alimentar dada à produção agrícola vem sendo utilizada como meio para o emprego de técnicas inovadoras, que demandariam 
maior tempo de estudos para a verificação de quão eficiente esse novo meio produtivo se mostra.

Entretanto, verifica-se que o uso de tais inovações demandaria estudos mais prolongados para a constatação de seus eventuais efeitos não somente sobre o cultivo, manutenção e colheita do produto agrícola, mas também referente aos reflexos quanto ao aparecimento de pragas mais resistentes ou até mesmo sobre as consequências sobre as populações humanas.

O presente estudo pretenderá demonstrar que os efeitos dos pesticidas agrícolas atingem reflexos não somente em seu uso desregulado no campo, mas também sobre as populações urbanas, indiretamente, e ocasiona um impacto sem precedentes na população rural que utiliza destes agrotóxicos diretamente.

Dados ofertados recentemente, tanto na utilização desses agrotóxicos em casos exemplificados na França e no Brasil, constatam que o dano ambiental e social está mais próximo do que as fontes governamentais ambientais desejam informar à população.

Há uma orquestração do lobby formado por tais indústrias para a consecução de um objetivo primário ante o alerta que deveria ser planejado pelo Poder Público, isto é, a tentativa de conscientização por esta indústria, por intermédio de signos diversos dos já consagrados que denotam o perigo do produto que comercializam.

Assim, há uma organização sistematizada por parte da indústria para a alteração das denominações de seus produtos, que ao invés de serem chamados por palavras que já contêm o sinal característico do perigo inerente ao produto como, por exemplo, os termos agrotóxicos, pesticidas, que denotam tal conteúdo negativo para a indústria, haveria a alteração desses termos para o que se pretende denominar de produtos fitosanitários ou para produtos de controle ambiental.

A decorrência disso seria solapar os esforços que estão sendo realizados por grupos organizados da sociedade civil no Brasil, e através de Eurodeputados franceses, no sentido de demonstrar os perigos carreados à população pela utilização de certos agrotóxicos ainda não estudados, ou cujos dados de contaminação não são repassados à sociedade, em nítida afronta ao princípio de governança aberta.

Os dados utilizados para a interligação de responsabilidades pelo uso de agrotóxicos à saúde da população em fatos concretos são, no mínimo, preocupantes, pois os danos ambientais e sociais não estão mais 
ligados ao futuro, mas são sentidos em na atualidade, de acordo com a apresentação das informações no decorrer do trabalho.

Procurar-se-á demonstrar, ainda, que a não submissão desses produtos de alta toxicidade a princípios ambientais e de saúde pública como, por exemplo, os princípios da prevenção e do limite, constantes da Declaração do Rio, durante a ECO/92, decorre da busca pelo lucro desmedido.

Uma nova sistematização econômica que incorra em maior preocupação com a existência digna do indivíduo e a justiça social, por intermédio da publicização de informações técnicas e dados corretos, por intermédio do governo, quanto aos danos ambientais e sociais ocasionados por tais produtos tóxicos, seria a mola propulsora para a utilização de novos sistemas de plantio que respeitem a integridade física e genética do ser humano, mas que também representaria possíveis prejuízos a marcas já consagradas, notadamente quanto à recente aquisição da Monsanto pela Bayer.

\section{1 \\ PROBLEMAS SOCIOAMBIENTAIS PROVOCADOS POR AGROTÓXICOS}

Há similitudes entre as situações enfrentadas pelo Brasil e pela França em relação aos agrotóxicos, como a inexistência de dados originados pelo governo sobre intoxicação de pessoas e do meio ambiente de forma indireta.

Os fatos concretos que serão abordados nesta seção são representativos de uma lacuna existente sobre uma informação precisa por parte do governo em relação ao uso de pesticidas nas lavouras.

Tais dados são alarmantes e demonstram desde o acometimento de enfermidades graves que levam fetos e pessoas a óbitos como, principalmente, na silenciosa intoxicação que acomete as pessoas de forma diversificada, independente de seu ramo de trabalho, seja na lida do campo ou não.

\subsection{FRANÇA}


O mercado agrícola francês utilizou, em 2014, sessenta mil toneladas de pesticidas, em um incremento de $9 \%$ sobre o ano anterior e que vem crescendo ano após ano. ${ }^{3}$

Como um verdadeiro "celeiro agrícola europeu", os agricultores franceses destinam, cada vez mais, recursos financeiros para a compra de agrotóxicos para o cultivo de seus produtos, com certa consciência quanto ao aumento da produção com a diminuição de pragas.

Entretanto, o fato obscuro do uso crescente de defensivos agrícolas é o aumento de danos físicos e genéticos que podem estar sendo carreados a esses indivíduos que lidam diretamente com tais produtos.

Há uma progressiva suspeita de que as moléculas de tais produtos possam causar doenças cancerígenas mutagênicas, além dos alertas quanto a doenças hematológicas malignas, câncer de próstata e de pele, de tumores cerebrais, doença de Parkinson e doença de Alzheimer, prejudicando, ainda, a reprodução humana e o desenvolvimento de crianças. ${ }^{4}$

Outra grave constatação é de que os tratoristas não estão a salvo do contato com agrotóxicos durante a aplicação dos produtos, tendo em vista que as cabines dos tratores não os isolam perfeitamente das partículas nanométricas, bem como a utilização de equipamentos de proteção individual durante o verão, acaba por aumentar a frequência cardíaca e respiratória dos aplicadores de pesticidas, o que aceleraria a passagem das toxinas pelo organismo do indivíduo. ${ }^{5}$

As vítimas não estão apenas na cadeia direta da lida com o pesticida, mas também se abate sobre aqueles que indiretamente têm contato com os agrotóxicos, como a sociedade como um todo que consome os produtos agrícolas tratados com defensivos, além de existir, sistematicamente, uma categoria de pessoas ainda mais sensíveis como as mulheres grávidas, lactantes e crianças.

Esse grupo de pessoas, que são expostas, indiretamente, sofre uma exposição em doses baixas, mas constantes, durante toda sua exis-

\footnotetext{
${ }^{3}$ VALO, Martin. Les agriculteurs, premières victimes des pesticides. Le Monde. Paris, France. Disponível em: <http://www.lemonde.fr/biodiversite/article/2016/06/23/lesagriculteurs-premieres-victimes-des-pesticides_4956586_1652692.html>. Acessado em 29/09/2016.

${ }^{4}$ Ibidem.

${ }^{5}$ Ibidem.
} 
tência, ocasionando o que foi chamado de "efeito cocktail"6, que não é considerado pelos órgãos ambientais governamentais.

O "efeito cocktail" corresponde ao seguinte, de acordo com William Bourguet, pesquisador no Centro de bioquímica estrutural do Montpellier (CNRS, Instituto Nacional de Saúde e Investigação Biomédica da Universidade de Montpellier):

O princípio geral é que duas substâncias, de forma isolada, podem ser inofensivas ou muito pouco ativas, mas podem tornar-se tóxicas quando misturadas. $^{7}$

O chamado "efeito cocktail" deve ser considerado como atuante em nosso cotidiano, tendo em vista que $97 \%$ dos alimentos contêm resíduos de pesticidas e, sorrateiramente, tal efeito vem destruindo organismos, uma vez que quando dos testes dos pesticidas pelas agências ambientais e de saúde, esses são realizados isoladamente, em cada produto, isto é, não há a noção da degradação gerada pelo "efeito cocktail", mas suspeitas quanto a alterações carcinogênicas, mutagênicas, desequilíbrio do sistema hormonal e problemas neurocomportamentais, o que não deve ser desprezado, uma vez que as crianças são expostas a 130 poluentes químicos por dia. ${ }^{8}$

\subsection{BRASIL}

O Brasil é o país campeão na utilização de agrotóxicos, segundo dados de $2013^{9}$, mantendo essa liderança desde $2008^{10}$, ou seja, por falta

\footnotetext{
${ }^{6}$ Disponível em: <http://www.lemonde.fr/planete/article/2016/02/03/pesticides-toxiquesinvisibles-et-omnipresents_4858846_3244.html>. Acessado em: 29/09/2016.

${ }^{7}$ FOUCART, Stéphane. Les secrets de l' effet cocktail mis au jour. Le Monde. Paris, France. Disponível em: <http://www.lemonde.fr/medecine/article/2015/09/03/les-secretsde-1-effet-cocktail-mis-au-jour_4744773_1650718.html>. Acesso em: 29/09/2016.

${ }^{8}$ Disponível em: <http://www.lemonde.fr/planete/article/2016/02/03/pesticides-toxiquesinvisibles-et-omnipresents_4858846_3244.html>. Acesso em 03/10/2016.

9 Disponível em: <https://lista10.org/diversos/os-10-paises-que-mais-utilizamagrotoxicos-no-mundo/>. Acesso em 04/10/2016.
} 
de mais dados, pode-se concluir que durante, pelo menos, cinco anos, vem sendo o país com maior utilização desses produtos.

O INCA (Instituto Nacional de Câncer José Alencar Gomes da Silva) publicou estudo, em que o país aparece com gastos na saúde na ordem de U\$10 bilhões, enquanto a França está em quinto lugar, com U $\$ 2,8$ bilhões, ${ }^{11}$ o que determina, em média, que cada brasileiro consome 7,3 litros de agrotóxicos por ano, com um incremento na utilização de 2000 a 2012 na ordem de $288 \% .^{12}$

De acordo com o instituto, a grande utilização de agrotóxicos no Brasil se deve à produção de sementes transgênicas, que necessitam de alta quantidade desses produtos para sua produção.

No Brasil, a ANVISA (Agência Nacional de Vigilância Sanitária), órgão competente para a análise dos agrotóxicos, examina menos de $50 \%$ destes produtos e ignora o mais utilizado, o glifosato.

O impasse brasileiro sobre o estudo desse herbicida constrata com a grande quantidade de pesquisas internacionais sobre o assunto. Há pesquisas em sentidos opostos.

A agência americana e a agência europeia recomendam a liberação da licença para utilização do glifosato por constatarem que não é cancerígeno $^{13}$ e a OMS, antes contrária a essa pesquisa, agora sinaliza no mesmo sentido ${ }^{14}$. Entretanto, a agência europeia faz uma ressalva de que o consumo seguro seria de "no máximo 0,5 miligramas por quilo de peso corporal. Ou seja, uma pessoa que pesa 80 quilos pode ingerir alimentos

\footnotetext{
${ }^{10}$ ROSSI, Marina. Agrotóxicos: o veneno que o Brasil ainda te incentiva a consumir. São Paulo, SP. Disponível em: <http://brasil.elpais.com/brasil/2016/03/03/politica/14570 29491_740118.html>. Acesso em 09/10/2016.

11 Disponível em: <https://lista10.org/diversos/os-10-paises-que-mais-utilizamagrotoxicos-no-mundo/>. Acesso em 04/10/2016.

${ }^{12}$ MADEIRO, Carlos. ANVISA analisa menos de 50\% dos agrotóxicos e ignora o mais usado no País. UOL Notícias. Maceió, AL. Disponível em: <http://noticias. uol.com.br/meio-ambiente/ultimas-noticias/redacao/2015/05/23/anvisa-analisa-menos-de50-dos-agrotoxicos-e-ignora-o-mais-usado-no-pais.html>. Acesso em 04/10/2016.

${ }^{13}$ Disponível em: <http://www.dw.com/pt-br/ag\%C3\%AAncia-europeia-diz-que-glifosato -n\%C3\%A3o-\%C3\%A9-cancer\%C3\%ADgeno/a-18846927>. Acessado em 09/10/2016.

${ }^{14}$ Disponível em <http://agenciabrasil.ebc.com.br/internacional/noticia/2016-05/oms-e-fa o-voltam-atras-e-dizem-que-glifosato-nao-provoca-cancer. Acessado em 09/10/2016>.
} 
que contenham no máximo 40 miligramas de resíduos de glifosato por dia". 15

A pesquisadora sênior do MIT, Dra. Stephanie Seneff, faz importante correlação entre a maior utilização do glifosato, ano após ano, e o estímulo do surgimento de casos de crianças autistas ${ }^{16}$, em uma proporção anual crescente e muito próxima ao constante aumento na utilização do herbicida.

Pesquisa realizada pela ANVISA (Agência Nacional de Vigilância Sanitária) aponta os alimentos mais contaminados por agrotóxicos: "92\% pimentões estudados estavam contaminados, seguidos do morango $(63 \%)$, pepino (57\%), alface (54\%), cenoura (49\%), abacaxi (32\%), beterraba $(32 \%)$ e mamão $(30 \%)$ ". ${ }^{17}$

A Defensoria Pública do Estado de São Paulo, por intermédio de uma solicitação dirigida ao Centro de Vigilância Sanitária, órgão integrante da Coordenadoria de Controle de Doenças da Secretaria de Estado da Saúde, disponibilizou informações sobre o monitoramente de agrotóxicos em alimentos coletados nas cidades de São Paulo e Campinas, de 2012 a $2014^{18}$, com a finalidade de realizar uma audiência pública que ocorreu nos dias 06 e 07 de outubro de 2016.

Pela importância dos dados, transcreve-se o texto a seguir:

De acordo com o levantamento, em 2012 foram analisadas 106 amostras, das quais 35 apresentaram situação insatisfaória quanto à presença de agrotóxicos; em 6 foram constatados agrotóxicos proibidos no exterior, como acefato e metamidofós. Em 2013, de 180 amostras, 30 se mostraram

\footnotetext{
${ }^{15}$ Disponível em: <http://www.dw.com/pt-br/ag\%C3\%AAncia-europeia-diz-que-glifosato -n\%C3\%A3o-\%C3\%A9-cancer\%C3\%ADgeno/a-18846927>. Acessado em 09/10/2016.

${ }^{16}$ MEYER, Nick. MIT Researcher's New Warning: at today's rate, half of all U.S. children will be autistic by 2025 . Disponível em: <http://themindunleashed.com/201 4/10/mit-researchers-new-warning-todays-rate-half-u-s-children-will-autistic-2025.html>. Acessado em 09/10/2016.

${ }^{17}$ ROSSI, Marina. O “alarmante" uso de agrotóxicos no Brasil atinge 70\% dos alimentos. El País. São Paulo, SP. Disponível em: <http://brasil.elpais.com/brasil/2015/04/29/politica/14303 21822_851653.html?rel= mas $>$. Acessado em 09/10/2016.

18 Disponível em: <http://dp-sp.jusbrasil.com.br/noticias/239611993/contaminacao-dealimentos-por-agrotoxicos-sera-tema-de-audiencia-publica-da-defensoria-publica-emsanto-andre>. Acessado em 09/10/2016.
} 
insatisfatórias e 11, com agrotóxicos proibidos no exterior.

Em 2014, das 167 amostras analisadas, 33 foram consideradas insatisfatórias (sendo que 62 laudos ainda não tinham sido liberados) e 13 continham agrotóxicos proibidos no exterior. Das amostras de alface, $60 \%$ foram consideradas insatisfatórias; o mesmo aconteceu com $70 \%$ das amostras de morango. ${ }^{19}$

Ao analisar o texto acima, constata-se que houve a manutenção do índice inicial de proporção entre amostras de alimentos e amostras insatisfatórias por conterem agrotóxicos, isto é, em 2012 a proporção era de 33\%; em 2013 houve queda para 16\%, mas, em 2014 a proporção voltou ao índice de 2012, demonstrando que não houve efetiva fiscalização das agências ambientais para o declínio constante das amostras insatisfatórias.

Em relação ao índice de agrotóxicos proibidos no exterior, mas encontrados nos alimentos brasileiros, esse apenas acentua sua elevação de amostras.

Em 2012, foram detectados agrotóxicos proibidos no exterior em seis amostras; em 2013 subiu para 11 amostras, em um aumento de 83,3\%, se comparadas com o ano anterior; e, em 2014 foram 13 amostras, sendo índice 116,7\% maior do que comparado a 2012.

Por sua vez, a Associação Brasileira de Defesa do Consumidor (PROTESTE), publicou dados que dão referência do descontrole na utilização de agrotóxicos no Brasil.

O teste realizado em 2016 aponta que mais de um terço dos alimentos $(37 \%)$ têm agrotóxicos ilegais, isto é, que não poderiam ser utilizados na produção de alimentos. ${ }^{20}$

Tais dados referem-se à contaminação indireta que permeia a população; quando em relação à população atingida diretamente pela intoxicação por agrotóxicos, a situação é bem pior.

19 Disponível em: <http://dp-sp.jusbrasil.com.br/noticias/239611993/contaminacao-dealimentos-por-agrotoxicos-sera-tema-de-audiencia-publica-da-defensoria-publica-emsanto-andre>. Acessado em 09/10/2016.

${ }^{20}$ Disponível em: <http://g1.globo.com/bom-dia-brasil/noticia/2016/11/teste-aponta-quemais-de-um-terco-dos-alimentos-tem-agrotoxicos-ilegais.html. Acessado em 04/11/2016> 
Segundo estudo da Universidade Federal do Rio Grande do Sul (UFRGS), o uso de agrotóxicos organofosforados, aumenta as chances de depressão dos agricultores, o que tem levado os agricultores a pôr fim às suas vidas por uma mescla de intoxicação por agrotóxicos, que leva à depressão, e dívidas, resultando no fato de que o Estado do Rio Grande do Sul seja o de maior índice de suicídios: 10 a cada 100 mil habitantes, sendo o dobro da taxa brasileira. ${ }^{21}$

A maior parte desses suicídios, taxa de $80 \%$ das mortes da cidade de Venâncio Aires, está ligada aos fumicultores, de acordo com a Comissão de Direitos Humanos da Assembleia Legislativa gaúcha e, em 2014, segundo a UFRGS, $20 \%$ dos agricultores entrevistados sofriam de depressão, ${ }^{22}$ o que se abate sobre as crianças, pois desde muito cedo essas têm contato com o trabalho agrícola e uma pesquisa do IBGE (Instituto Brasileiro de Geografia e Estatística) aponta que em 2010, 39.659 crianças de 10 a 13 anos trabalhavam nesse ramo.

Portanto, os problemas encontrados tanto na França quanto no Brasil são muito semelhantes, mas ao analisar a informação, depara-se com uma nítida diferença de tratamento quanto à abertura e dispersão das informações, conforme pretender-se-á evidenciar a seguir.

\section{INEFICIÊNCIA DA GOVERNANÇA ABERTA OU INTERESSE NO OBSTÁCULO Å INFORMAÇÃO?}

Ao analisar o tema, de antemão é oportunizada a análise de problema análogo que ocorre nos Estados Unidos da América desde 2012, quando iniciou a prospecção de gases de xisto como nova matriz energética do País.

Com a prospecção sendo realizada por empresas de grande eficiência produtiva e de propaganda proativa do bem prospectado, estabeleceu-se a imposição da mídia sobre o assunto, mitigando ou até mesmo fazendo uma propaganda maciça contra os opositores em relação à utili-

\footnotetext{
${ }^{21}$ SPERB, Paula. 'Bomba-relógio' de suicídios: Como uma mescla de agrotóxicos, depressão e dívidas abala grupo de agricultores gaúchos. BBC Brasil, Porto Alegre, RS. Disponível em <http://noticias.uol.com.br/saude/ultimas-noticias/bbc/2016/10/04/bomba-relog io-de-suicidios-como-uma-mescla-de-agrotoxicos-depressao-e-dividas-abala-grupo-deagricultores-gauchos.html>. Acessado em 09/10/2016.
}

${ }^{22}$ Ibidem. 
zação desse tipo de gás, em virtude dos graves danos ambientais que a retirada do gás de xisto causava.

Essa linha de pensamento utilizado pelas empresas é a da necessidade de se obter outras fontes de energia, aumentando a capacidade energética do País e tornando-a mais barata, em comparação com outras, e, ao mesmo tempo, distribuí-la sem qualquer preocupação com a possibilidade de queda de oferta ao cidadão, já que a capacidade de geração era aumentada em demasia com a nova oferta.

O problema enfrentado pelo presente trabalho demonstra justamente o mesmo tratamento que a indústria de pesticidas agrícolas demanda à sociedade, pois de um lado acena com a diminuição dos custos no combate às pragas e aumento da produção agrícola e, de outro lado, enaltece a obrigação em aumentar a produção agrícola para saciar a fome mundial, de forma a oportunizar o acesso à alimentação.

Esse jogo que se forma, com a ajuda do governo, que ou não possui dados concretos sobre os perigos no emprego de certos agrotóxicos ou, realmente, não repassa à sociedade esses dados, determina a intoxicação das pessoas e do meio ambiente, em total afronta aos princípios ambientais e à Declaração Universal dos Direitos Humanos.

\subsection{OS PRINCÍPIOS AMBIENTAIS COMO GARANTIA AO CUMPRIMENTO DOS DIREITOS HUMANOS, EM QUEDA}

Inquestionável que a Declaração Universal dos Direitos Humanos consagra em seus artigos XIX, XXIII e XXV uma série de direitos que são afrontados e mutilados pelos vários casos apontados na primeira seção deste trabalho.

$\mathrm{O}$ artigo XXIII declara que todo ser humano deve ter condições justas e favoráveis de trabalho, o que deve gerar, através de seu labor, condições de saúde e bem-estar a ele e à sua família (artigo XXV) e, para coroar a busca para que tais direitos se tornem efetivos, o trabalhador dever ter acesso a informações por quaisquer meios (artigo XIX).

Talvez aqui resida o direito mais precioso à junção dessas três garantias essenciais ao pleno desenvolvimento do ser humano: o direito de acesso à informação. 
Os dados colhidos na primeira parte do trabalho demonstram exatamente que a ausência da informação garantiu a um sem número de pessoas a retirada de sua dignidade, seja pela antecipação de uma situação de extrema penúria física ou mental originada pelo uso do agrotóxico, seja pelo total impedimento na continuidade da vida laborativa pelo encerramento da própria vida.

Portanto, tal infringência coloca em risco os próprios Direitos Humanos, pois maculada a informação, depara-se com o enfraquecimento do direito do indivíduo ao trabalho e todos os reflexos decorrentes disso, ou seja, condições justas e favoráveis ao trabalho e, em consequência desse, também ao acesso a condições de saúde e bem-estar.

Coloca-se em risco o item 08 da Declaração e Programa de Ação de Viena da Conferência Mundial sobre os Direitos Humanos, de 1993, a qual assevera: "A democracia, o desenvolvimento e o respeito aos direitos humanos e liberdades fundamentais são conceitos interdependentes que se reforçam mutuamente".

Ricardo Sayeg, ao comentar o item acima, enfatiza o seguinte:

Tal consciência global consubstancia o espírito objetivo que exige um planeta de homens livres, iguais e fraternos, além de objetivamente pacífico, inclusivo e emancipador, estruturado em uma ordem jurídica monista de direitos humanos que prevalece sobre qualquer ordem jurídica nacional e internamente adotada. ${ }^{23}$

Daí estabelece-se que a Democracia, citada amplamente no item 08 e também intrinsecamente na obra de Sayeg, como o único regime que compatibiliza os Direitos Humanos, principalmente os citados acima e, ao colocar em risco tais direitos, coloca em risco a própria Democracia, ante o expressivo poder econômico que praticamente impõe uma conduta laborativa ao indivíduo que o segrega e o põe em situação marginal ao exercício de quaisquer desses direitos, em notório Estado de Exceção.

Essa exceção vivenciada remete ao poder e sendo realizada através de novas roupagens, busca o único fim de aprisionar o indivíduo a

23 SAYEG, Ricardo; BALERA, Wagner. O capitalismo humanista. São Paulo: KBR, 2011, e-book, p. 37. 
novos entendimentos que suplantam as garantias dos Direitos Humanos, mas que se encontram com interesses individuais primitivos, tal como nessas sociedades. O fim é o da retomada ou manutenção do poder em detrimento de um regime de democracia participativa representada em um ordenamento jurídico suplantado por estratagemas jurídicos.

Agamben aponta o termo iustitium para representar o Estado de Exceção por relação com o evento da natureza designado de solstitium (solstício), que marca a época do ano em que o astro-rei, o Sol, está mais distante da Terra, importando na analogia das noites mais longas e, portanto, mais frias, como o momento de vazio jurídico, de "suspensão não simplesmente da administração da justiça, mas do direito como tal". ${ }^{24}$

Todos os fatos e dados citados e exemplificados no trabalho deixam à deriva o indivíduo que sequer pode decidir sobre colocar sua vida em risco. Note: a ausência de acesso à informação escraviza o indivíduo a uma vida laborativa que coloca em xeque todas as garantias da Declaração Universal dos Direitos Humanos, citadas acima, como a própria Democracia.

Essa perplexidade que atormenta o ser humano é tema de Agamben quando esse o analisa em sua obra Homo Sacer e aponta a dualidade intrínseca ao Ser: "augusto e maldito, digno de veneração e suscitante de horror". 25

Assim, a sessão de 16 de fevereiro de 1946 do Conselho Econômico e Social das Nações Unidas, determinou, de acordo com a citação de Comparato $^{26}$, ao transcrever os dizeres de um dos delegados presentes à sessão, a necessidade imperiosa de se criar "uma maquinaria adequada para assegurar o respeito aos direitos humanos e tratar os casos de sua violação". Transparece que essa "maquinaria" vem falhando com o passar dos tempos por ser alvo da busca do poder e lucro a qualquer custo.

Entretanto, os princípios do Direito Ambiental podem dar efetividade a essas garantias no cumprimento de um princípio dos mais fundamentais dessa área: o princípio da prevenção.

\footnotetext{
${ }^{24}$ AGAMBEN, Giorgio. Estado de excepção. Lisboa: Edições 70, 2003, p. 68.

${ }^{25}$ AGAMBEN, Giorgio. Homo sacer: o poder soberano e a vida nua. Belo Horizonte: UFMG, 2002, p. 80.

${ }^{26}$ COMPARATO, Fábio Konder. A afirmação histórica dos direitos humanos. São Paulo: Saraiva, 2004, p. 222.
} 
Tal princípio nasce da Conferência Ambiental Internacional ECO/92, realizada no Rio de Janeiro, quando o item quinze da conferência estipulou da seguinte forma:

De modo a proteger o meio ambiente, o princípio da precaução deve ser amplamente observado pelos Estados, de acordo com suas capacidades. Quando houver ameaça de danos sérios ou irreversíveis, a ausência de absoluta certeza científica não deve ser utilizada como razão para postergar medidas eficazes e economicamente viáveis para prevenir a degradação ambiental.

Ana Flávia Barros Platiau destaca o seguinte sobre o princípio:

[...] foi consagrado no direito internacional ambiental com a missão de dotar legisladores e líderes políticos de um instrumento de regulação internacional da inovação tecnológica e da atividade antrópica de uma maneira geral. Porém, foi criado dentro de um contexto jurídico que evolui lentamente em comparação ao progresso da biotecnologia e da demanda social por certezas científicas sobre essas questões. ${ }^{27}$

Portanto, em caso de dúvidas sobre determinado produto, esse deve ser substituído ou mesmo proibida sua utilização, tendo em vista que o meio ambiente, além do natural, deve ser preservado em suas várias espécies, na tentativa de que o ser humano, integrante desse meio, seja poupado das atrocidades ocasionadas pelo próprio ser, em razão da dualidade enfrentada pelos indivíduos, conforme citado através de Agamben.

Importante salientar que essa limitação à utilização de produtos cujos efeitos no meio ambiente e no próprio ser humano ainda são desconhecidos, não confronta com o princípio do desenvolvimento sustentável, mas se coaduna perfeitamente com esse, tendo em vista que a ideia central é o desenvolvimento responsável e vinculado a métodos produtivos que utilizem a tecnologia como meio de gerar menor degradação ambien-

${ }^{27}$ Apud Paulo de Bessa Antunes. Direito ambiental. São Paulo: GEN, 2014, p. 30. 
tal. Nítido que o termo desenvolvimento, nos dias atuais, deve ter essa conotação.

Nesse sentido, a Declaração de Estocolmo para o Meio Ambiente Humano contém o seguinte:

O crescimento natural da população coloca continuamente, problemas relativos à preservação do meio ambiente, e devem-se adotar as normas e medidas apropriadas para enfrentar esses problemas. De todas as coisas do mundo, os seres humanos são a mais valiosa. Eles são os que promovem o progresso social, criam riqueza social, desenvolvem a ciência e a tecnologia e, com seu árduo trabalho, transformam continuamente o meio ambiente humano. Com o progresso social e os avanços da produção, da ciência e da tecnologia, a capacidade do homem de melhorar o meio ambiente aumenta a cada dia que passa.

Já em seu primeiro princípio, a ECO/92 reafirma tal prioridade: "Os seres humanos estão no centro das preocupações com o desenvolvimento sustentável. Têm direito a uma vida saudável e produtiva em harmonia com a natureza".

Dessa forma, os princípios de direito ambiental reproduzem as garantias previstas na Declaração dos Direitos Humanos e, por intermédio desses princípios, aceitos internacionalmente, devem impor uma nova energização dos Direitos Humanos, que vem se combalindo ante a economicidade e a busca do poder através do lucro a qualquer custo, inclusive do desprezo aos Direitos Humanos.

\section{CONSIDERAÇÕES FINAIS}

Há semelhanças no desenrolar dos problemas havidos pelo uso de agrotóxicos tanto no Brasil quanto na França.

A desinformação prestada pelo governo, nos dois países, é que parece ter objetivos diferentes. 
Enquanto na França há uma dispersão de dados oferecidos pelo próprio governo, por intermédio da governança aberta que existe no País, no Brasil a situação se inverte. O detalhamento dos dados no Brasil não passa, diretamente, pelo próprio governo, mas por intermédio de outros organismos que propagam tal informação, sejam organizações não governamentais, a imprensa ou órgãos do poder público mais identificados com a sociedade.

Assim, o levantamento de dados faz surgir essa distinção sobre o que será concluído ao final, em relação aos dados apurados quanto à utilização dos agrotóxicos: ineficiência da governança aberta ou interesse no obstáculo à informação?

Além desse questionamento, questiona-se ainda se o cerceamento da informação em relação ao indivíduo não seria um ato atentatório à própria democracia.

De fato, conforme amplamente pesquisado, infere-se que, na França, os órgãos governamentais de saúde divulgam essas informações em escala, de forma que o indivíduo tenha conhecimento quanto a decidir sobre o tipo de alimentação que queira ingerir, bem como quanto ao tipo de trabalho que queira laborar.

Essa possibilidade de escolha denota o intento democrático em vigor, tendo em vista que propicia ao cidadão a escolha de trabalhar na agricultura ou não, sabedor dos riscos conferidos pela utilização de pesticidas.

No Brasil, inexiste essa governança aberta, isto é, a ausência de informações por parte do governo subtrai ao indivíduo (que aqui não se denomina cidadão pelo próprio tratamento que lhe é ofertado) a ciência, o conhecimento em decidir seu futuro, gerando a lesão pela imposição de uma política omissa em relação à prestação da informação.

Ora, o princípio democrático é afrontado ao marginalizar o indivíduo em relação à possibilidade de escolha quanto ao seu futuro e quanto a questionar as práticas realizadas ou não pelo governo.

Quando o artigo XXIII declara que todo ser humano deve ter condições justas e favoráveis de trabalho, que deve gerar como resultado, boas condições de saúde e bem-estar a ele e à sua família (artigo XXV) e, que, para que tais direitos se tornem efetivos, o trabalhador dever ter acesso a informações por quaisquer meios (artigo XIX), apresenta-se, com a ausência de tais informações, a lesão ao presente e ao futuro do 
indivíduo, pois lhe é extirpado o conhecimento necessário para zelar por seus direitos.

Assim, entende-se pela pesquisa realizada, que o governo francês possui ineficiência na governança aberta, pois os riscos estão presentes e conhecidos pela sociedade, mas pouco foi implementado para que esse dano cesse, apesar de um avanço expressivo em comparação com a realidade brasileira.

Em relação ao governo brasileiro, percebe-se a obstaculização da informação, uma vez que, apesar da ciência por parte do governo dos riscos na adoção dos agrotóxicos, pouco se tem feito para controlar sua utilização, pois não há veiculação dos dados que expressam o emprego de pesticidas no País e que ainda são usados na produção de alimentos. Denota-se, assim, a ausência de informes repassados para a sociedade pelos canais oficiais, determinando uma situação de penúria quanto ao acesso de informação e a seletivização dessa para aqueles que buscam tal conhecimento através de outros recursos.

\section{REFERÊNCIAS BIBLIOGRÁFICAS}

AGAMBEN, Giorgio. Estado de excepção. Lisboa: Edições 70, 2003. Homo sacer: o poder soberano e a vida nua. Belo Horizonte: UFMG, 2002, p. 80.

ANTUNES, Paulo de Bessa. Direito ambiental. São Paulo: GEN, 2014. COMPARATO, Fábio Konder. A afirmação histórica dos direitos humanos. São Paulo: Saraiva, 2004.

Disponível em <http://agenciabrasil.ebc.com.br/internacional/noticia/201

6-05/oms-e-fao-voltam-atras-e-dizem-que-glifosato-nao-provocacancer. Acessado em 09/10/2016>.

Disponível em: <http://g1.globo.com/bom-dia-brasil/noticia/2016/11/ teste-aponta-que-mais-de-um-terco-dos-alimentos-temagrotoxicos-ilegais.html. Acessado em 04/11/2016>.

Disponível em: <http://www.dw.com/pt-br/ag\%C3\%AAncia-europeiadiz-que-glifosato-n\%C3\%A3o-\%C3\%A9-cancer\%C3\%ADgeno/a18846927>. Acessado em 09/10/2016.

Disponível em: <http://www.lemonde.fr/planete/article/2016/02/03/pesti cides-toxiques-invisibles-et-omnipresents_4858846_3244.html>. Acessado em: 29/09/2016. 
Disponível em: https://lista10.org/diversos/os-10-paises-que-mais-utiliz am-agrotoxicos-no-mundo/. Acesso em 04/10/2016.

FOUCART, Stéphane. Les secrets de l' effet cocktail mis au jour. Le Monde. Paris, France. Disponível em: <http://www.lemonde.fr/me decine/article/2015/09/03/les-secrets-de-l-effet-cocktail-mis-au-jou r_4744773_1650718.html>. Acesso em: 29/09/2016.

MADEIRO, Carlos. ANVISA analisa menos de $\mathbf{5 0 \%}$ dos agrotóxicos e ignora o mais usado no País. UOL Notícias. Maceió, AL. Disponível em: <http://noticias.uol.com.br/meio-ambiente/ultimasnoticias/redacao/2015/05/23/anvisa-analisa-menos-de-50-dos-

agrotoxicos-e-ignora-o-mais-usado-no-pais.html>. Acesso em 04/10/2016.

SAYEG, Ricardo; BALERA, Wagner. O capitalismo humanista. São Paulo: KBR, 2011, e-book, p. 37.

SPERB, Paula. 'Bomba-relógio' de suicídios: Como uma mescla de agrotóxicos, depressão e dívidas abala grupo de agricultores gaúchos. BBC Brasil, Porto Alegre, RS. Disponível em <http://noticias.uol.com.br/saude/ultimas-noticias/bbc/2016/10/04/ bomba-relogio-de-suicidios-como-uma-mescla-de-agrotoxicos-dep ressao-e-dividas-abala-grupo-de-agricultores-gauchos.html>. Acessado em 09/10/2016.

VALO, Martin. Les agriculteurs, premières victimes des pesticides. Le Monde. Paris, France. Disponível em: http://www.lemonde.fr/ biodiversite/article/2016/06/23/les-agriculteurs-premieres-victimesdes-pesticides_4956586_1652692.html. Acessado em 29/09/2016. 